\title{
Analisis Efesiensi Tataniaga Kopi di Desa Ngarip Kecamatan Ulubelu Kabupaten Tanggamus
}

\section{Analysis of Coffee Marketing Efficiency in Ngarip Village, Ulubelu Subdistrict, Tanggamus Regency}

\author{
Mohammad Welly Justiceawan ${ }^{1 *}$, Marlinda Apriyani ${ }^{1}$, Fadila Marga Saty ${ }^{1}$ \\ State Polytechnic of Lampung \\ *E-mail : mwelly19@gmail.com
}

\begin{abstract}
The research aimed to analyze coffee marketing channels in Ngarip Village, Ulubelu Subdistrict, Tanggamus Regency, analyze marketing margins, and analyze Marketing Efficiency. The method used was a survey method using questionnaires and the data used were quantitative and qualitative data. The results of the study showed that there were 2 coffee marketing channels, named channel 1 (farmers - KUB - consumers) and channel 2 (farmers - collectors - KUB - consumers). Marketing Channel 1 is more efficient than marketing channel 2. Marketing farmer's share of Channel 1 is greater than marketing channel 2 but farmer's price comparison is low compared to that received by consumers at the Village level. The results of the marketing margin and Farmer's share showed that channel 1 marketing margin was Rp. 17,730 and farmer's share was 98\% while channel 2 marketing margin was Rp. 17,730 and farmer's share was (95\%).
\end{abstract}

Keywords: Coffee, marketing, channel, efficiency, margin.

Disubmit : 13 Januari 2020, Diterima: 2 Februari 2020, Disetujui : 14 April 2020

\section{PENDAHULUAN}

Kopi (Coffea sp.) adalah spesies tanaman berbentuk pohon yang termasuk dalam family Rubiaceae dan genus Coffea. Kopi robusta bisa ditanam pada ketinggian lahan yang lebih rendah dari kopi arabika agar dapat tumbuh dan berproduksi dengan baik. Penanaman kopi robusta pada lahan dataran rendah akan menurunkan produksi dan lebih rentan terhadap penyakit karat daun, di daerah Lampung penanaman robusta cocok ditanam pada ketinggian antara 300 - 600 mdpl. Produksi kopi robusta Kabupaten Tanggamus mencapai 23 persen dari seluruh produksi kopi robusta di Provinsi Lampung yaitu 131.501 ton dengan luas daerah 173.690 ha (BPS Lampung, 2018). Kabupaten Tanggamus juga merupakan salah satu kabupaten yang memiliki jumlah koperasi dalam status aktif yang kegiatannya mengolah kopi robusta dan sebagain besar anggotanya bermatapencaharian sebagai petani kopi robusta (Utami dk, 2019).

Tataniaga adalah suatu sistem total dari kegiatan bisnis yang dirancang untuk merencanakan, menentukan harga, mempromosikan dan mendistribusikan barang-barang yang dapat memuaskan keinginan dan jasa baik kepada para konsumen saat ini maupun konsumen potensial (Rachmawati, 2011). Desa Ngarip dipilih dengan sengaja (purposive) didasarkan pertimbangan bahwa Desa Ngarip merupakan salah satu sentra produksi kopi di Kabupaten Tanggamus. Saluran tataniaga yang kopi di Desa Ngarip Kecamatan Ulubelu Kabupaten Tanggamus ada 2, yaitu saluran pertama melalui petani - Kelompok Usaha Bersama 
(KUB) - konsumen dan saluran kedua melalui petani - pengepul - Kelompok Usaha Bersama (KUB) konsumen.

KUB dibentuk untuk menyimpan dan menjual kopi sebelum dijual kembali ke konsumen. Akses informasi pasar bervariasi di tingkat petani. Hal ini karena posisi tawar petani sebagai penerima harga. Petani kopi di Desa Ngarip umumnya cenderung menjual produk ke pengepul bukan KUB. Hal ini menyebabkan petani mendapatkan margin yang berbeda beda, sehingga bagian harga yang diterima petani juga bervariasi. Marjin tataniaga adalah perbedaan harga yang ditawarkan produsen dengan harga yang dibayar oleh konsumen akhir. Besar kecilnya marjin tataniaga dipengaruhi oleh perubahan biaya tataniaga, keuntungan pedagang perantara, harga yang dibayar konsumen akhir dan harga yang diterima produsen (Astuti, 2014). Bagian harga yang diterima petani (Farmer's share) merupakan perbandingan harga yang diterima oleh petani kopi dengan harga yang dibayarkan oleh konsumen. Farmer's share memiliki korelasi yang negatif dengan marjin tataniaga, artinya semakin tinnggi marjin tataniaga maka bagian harga yang diterima petani semakin rendah (Arwati, 2016). Oleh karena itu, penelitian ini bertujuan untuk menggambarkan kondisi efesiensi tataniaga kopi di Desa Ngarip Kecamatan Ulubelu Kabupaten Tanggamus.

\section{METODE PENELITIAN}

Penelitian ini dilaksanakan di Desa Ngarip, Kecamatan Ulubelu, Kabupaten Tanggamus, Provinsi Lampung. Penelitian ini menggunakan metode survei dengan menggunakan kuesioner. Jumlah Responden petani dalam penelitian ini dipilih dari populasi 2 kelompok petani kopi yang masih aktif di Desa Ngarip sebanyak 60 petani. Petani kopi responden penelitian ini merupakan sampel minimal (20\% dari populasi) sebanyak 12 petani kopi. Responden pelaku pengepul sebanyak 2 orang dan perwakilan dari pengelola KUB. Data penelitian ini adalah data primer meliputi informasi saluran tataniaga, marjin tataniaga dan efesiensi pemasasaran. Metode analisis data dengan analisis aaluran tataniaga, margin tataniaga dan ratio keuntungan dan biaya. Saluran tataniaga kopi di Desa Ngarip dengan menggunakan metode deskriptif. Analisis saluran tataniaga diamati melalui petani, pengepul, KUB dan konsumen yang turut berkontribusi pada penyaluran atau transformasi hasil panen dari produsen ke konsumen akhir. Besarnya marjin tataniaga yang diterima oleh setiap lembaga tataniaga menggunakan formula (Fitriani, dkk., 2012; Noer, dkk, 2012) (Imelda, Dani Apriono, 2014) sebagai berikut:

$$
\begin{aligned}
& \mathrm{M}=\mathrm{Psi}-\mathrm{Pbi} \\
& \mathrm{M}=\mathrm{Ci}+\prod \mathrm{i} \ldots . .
\end{aligned}
$$

\section{Keterangan:}

$\mathrm{M}=$ Marjin tataniaga di tingkat ke-i

Ps = Harga jual di tingkat ke-i

$\mathrm{Pb}=$ Harga beli di tingkat ke-i

$\mathrm{C}=$ Biaya tataniaga tingkat ke-i

$\Pi=$ Keuntungan lembaga tataniaga pasar tingkat ke-i

Nilai Farmer`s share yang diterima pihak produsen dan konsumen dirumuskan sebagai berikut (Astuti, 2014) :

$$
\mathrm{Sp}=\frac{p_{T}}{\mu r} \times 100 \%
$$

Keterangan:

$\mathrm{Sp}=$ Farmer`s share (dalam persentase)

$\mathrm{Pf}=$ Harga di tingkat petani kopi $(\mathrm{Rp})$

$\operatorname{Pr}=$ Harga yang dibayarkan oleh konsumen kopi (Rp)

Analisis Rasio Keuntungan dan Biaya Untuk mengetahui penyebaran rasio keuntungan dan biaya pada masing-masing lembaga tataniaga dapat dirumuskan sebagai berikut (Gultom,1996) : 


$$
\mathrm{R} / \mathrm{Cratio}=\frac{\mathrm{Ll}}{\mathrm{Cl}} \mathrm{X}
$$

Keterangan :

Li : Keuntungan lembaga tataniaga ke-i

$\mathrm{Ci}$ : Biaya tataniaga lembaga ke-i

\section{HASIL DAN PEMBAHASA N}

Responden dalam penelitian ini adalah 15 orang yang terdiri dari 12 petani, 2 pengepul dan $1 \mathrm{KUB}$. Karakteristik responden penelitian ini dibagi menjadi 3 karakteristik yaitu: berdasarkan usia, pendidikan dan pengalaman berusaha. Petani responden pada penelitian ini sebagian besar berada pada rentang usia 26-40 tahun dan pengepul 2 orang berumur 29 dan 53 tahun. Usia merupakan salah satu indikator produktif atau tidaknya manusia untuk mengelola usahanya (Yulida, 2012). Karakteristik tingkat pendidikan bahwa responden yang sebagian besar adalah jenjang pendidikan pendidikan menengah pertama (SMP). Tingkat pendidikan seseorang yang semakin tinggi akan membantu pengetahuan tentang pengelolaan usahataninya (Yulida, 2012).

Berdasarkan pengalaman berusaha, responden sebagian besar sudah lama melakukan kegiatan usahatanikopi rata-rata berpengalaman lebih dari 10 tahun. Pengalaman tersebut berguna untuk menyelesaikan permasalahan yang sudah mereka jalankan 10 tahun sehingga usahataninya ke depan semakin baik dari tahun-tahun sebelummya walaupun memiliki riwayat pendidikan yang tidak tinggi tetapi dapat mengelola usahanya dengan cukup baik.

Memahami saluran tataniaga kopi di Desa Ngarip merupakan penelurusan aspek sosial sebagai landasan yang mendasari petani menjual hasil panen mereka ke pengepul. Sebagaian petani mengambil sarana produksi dan bahan-bahan untuk memenuhui kebutuhan kebun mereka hingga panen. Selain juga petani sering dibantu oleh pengepul dalam memenuhi kebutuhan sehari-hari seperti biaya sekolah anak. Kondisi ini menyebabkan petani tidak memiliki pilihan pada waktu panen kopi. Petani harus menjual hasilnya ke pengepul untuk menutupi biaya yang dipinjamkan oleh pengepul. Petani merupakan gambaran Client saluran yang terkadang kurang mampu dan pengepul sebagai orang yang mempunyai uang (Patron) kemudian keduanya membuat relasi pertukaran hutang piutang dan jasa sehingga petani dan pengepul memiliki keterikatan sosial (Fuad, Aenurofik and Rosyid, 2015).

Lembaga tataniaga adalah badan usaha atau individu yang menyelenggarakan tataniaga, menyalurkan jasa dan komoditi yang dipasarkan dalam usahanya, seperti petani, pengepul, KUB dan kosumen akhir (Imelda, Dani Apriono, 2014). Saluran tataniaga merupakan serangkaian kegiatan beberapa lembaga tataniaga yang berkaitan satu sama lainnya yang akan menyalurkan biji kopi ke tangan konsumen akhir. Produsen (petani) memiliki peranan yang sangat penting dalam menyediakan biji kopi dan melakukan kegiatan penyaluran tataniaga ke tangan KUB. Sementara pedagang atau pengepul (KUB) memiliki peranan untuk menyalurkan biji kopi sampai ketangan konsumen akhir, terdapat dua salauran tataniaga kopi yang ada di Desa Ngarip yaitu (1) Petani - KUB - Konsumen dan (2) Petani - Pengepul - KUB - Konsumen.

Harga rata-rata yang diterima petani apabila menjual biji kopi kepengepul adalah Rp 21.000-, sedangkan apabila petani menjual biji kopi langsung ke KUB adalah Rp 21.500-,. KUB memberi harga yang lebih tinggi dibandingkan pengepul. Harga kopi jika petani menjual produk langsung ke KUB adalah Rp21.500/kg sedangkan petani menjual produk tersebut ke pengepul petani mendapatkan Rp21.000/kg. Namun, karena relasi sosial yang terbangun antara petani kopi dengan pengepul membuat petani menyerahkan hasil panennya kepada pengepul dibanding ke KUB.

Margin tataniaga merupakan selisih harga yang dibayarkan oleh konsumen dengan harga yang diterima produsen (Prayitno, A.B, 2013). Hal itu terjadi karena lembaga tersebut melakukan kegiatan yang 


\section{Journal of Food System and Agribusiness}

membutuhkan biaya untuk melakukan tataniaga dari produsen kekonsumen. Margin tataniaga bisa diartikan sebagai selisih harga suatu barang yang terjadi pada lembaga tataniaga yang terkait didalamnya.

Tabel 1. Perhitungan margin tataniaga kopi di Desa Ngarip

\begin{tabular}{|c|c|c|c|c|c|c|}
\hline \multirow[b]{2}{*}{ No } & \multirow{2}{*}{$\begin{array}{l}\text { Lembaga } \\
\text { tataniaga }\end{array}$} & \multirow[b]{2}{*}{ Uraian } & \multicolumn{2}{|c|}{ Saluran 1} & \multicolumn{2}{|c|}{ Saluran 2} \\
\hline & & & $\begin{array}{l}\text { Harga } \\
(\mathrm{Rp} / \mathrm{Kg})\end{array}$ & Persentase & $\begin{array}{l}\text { Harga } \\
(\mathrm{Rp} / \mathrm{kg})\end{array}$ & Persentase \\
\hline \multirow[t]{5}{*}{1} & \multirow[t]{5}{*}{ Petani } & Biaya produksi & 4.270 & 19,9 & 4.270 & 20,3 \\
\hline & & Biaya Tataniaga & 727 & 3,4 & 600 & 2,9 \\
\hline & & Keuntungan & 16.503 & 77 & 16.130 & 76 \\
\hline & & Harga Jual & 21.500 & 100 & 21.000 & 100 \\
\hline & & Margin Tataniaga & 17.230 & 80,1 & 16.730 & 79,6 \\
\hline \multirow[t]{5}{*}{2} & \multirow[t]{5}{*}{ Pengepul } & Harga beli & - & - & 21.000 & 97,6 \\
\hline & & Biaya tataniaga & - & - & 103 & 0,5 \\
\hline & & Keuntungan & - & - & 39,7 & 1,8 \\
\hline & & Harga Jual & - & - & 21.500 & 100 \\
\hline & & Margin Tataniaga & - & - & 500 & 2,3 \\
\hline \multirow[t]{5}{*}{3} & \multirow[t]{5}{*}{ KUB } & Harga Beli & 21.500 & 98 & 21.500 & 98 \\
\hline & & Biaya Tataniaga & 140 & 0,6 & 140 & 0,6 \\
\hline & & Keuntungan & 360 & 1,6 & 360 & 1,6 \\
\hline & & Harga Jual & 22.000 & 100 & 22.000 & 100 \\
\hline & & Margin Tataniaga & 500 & 2,3 & 500 & 2,3 \\
\hline 4 & \multicolumn{2}{|c|}{ Total Biaya $(\mathrm{Rp} / \mathrm{Kg})$} & 867 & 4 & 843 & 4 \\
\hline 5 & \multicolumn{2}{|c|}{ Total Keuntungan(Rp/Kg) } & 16.863 & 78,6 & 16.887 & 79 \\
\hline 6 & \multicolumn{2}{|c|}{ Total Margin $(\mathrm{Rp} / \mathrm{Kg})$} & 17.730 & 82,4 & 17.730 & 84,2 \\
\hline
\end{tabular}

Nilai margin tataniaga dihitung berdasarkan saluran tataniaga yang ada, yaitu saluran tataniaga 1 dan saluran tataniaga 2. Hasil perhitungan dapat dilihat pada Tabel 6 di bawah ini.

Tabel 2. Hasil perhitungan margin tataniaga kopi di Desa Ngarip

\begin{tabular}{lc}
\hline Saluran Tataniaga & Margin Tataniaga $(\mathbf{R p} / \mathbf{K g})$ \\
\hline Saluran Tataniaga 1 & 17.730 \\
Saluran Tataniaga 2 & 17.730 \\
\hline
\end{tabular}

Sumber data Primer, 2019.

Tabel 2 menunjukan bahwa perbandingan kedua margin tataniaga memiliki perbedaan nilai. Saluran Tataniaga 1 dan 2 memiliki nilai margin sebesar Rp.17.730/kg. Berdasarkan data di atas tidak terdapat perbedaan margin, akan tetapi keuntungan dari kedua margin tersebut menunjukan perbedaan. Margin tataniaga yang besar akan berpengaruh terhadap harga yang diterima. Tataniaga dapat dikatakan efesien apabila barang dari produsen ke tangan konsumen akhir dengan biaya-biaya semurah-murahnya. (Nainggolan, Suyatno and Hutajulu, 2017)

Farmer's Share adalah bagian yang diterima produsen, semakin besar nilai Farmer's Share dan semakin kecil margin tataniaga maka tataniaga dikatakan efesiensi (Handayani and Nurlaila, 2011). Farmer's share dari dua saluran tataniaga kopi yang ada di Desa Ngarip dapat dilihat pada Tabel 3. Harga konsumen merupakan komsumen di tingkat Desa Ngarip. 
Tabel. 3 Farmer's Share kopi di Desa Ngarip

\begin{tabular}{cccc}
\hline & \multicolumn{2}{c}{ Harga } & \\
\cline { 2 - 3 } Saluran Tataniaga & $\begin{array}{c}\text { Tingkat } \\
\text { Petani(Rp/Kg) }\end{array}$ & $\begin{array}{c}\text { Tingkat } \\
\text { Konsumen(Rp/Kg) }\end{array}$ & Farmer Share(\%) \\
\hline Saluran 1 & 21.500 & 22.000 & 98 \\
Saluran 2 & 21.000 & 22.000 & 95
\end{tabular}

Sumber data Primer, 2019.

Harga produk pertanian merupakan harga yang fluktuatif atu berubah-ubah, begitu juga dengan harga jual kopi di Desa Ngarip. Setiap transaksi penjualan yang ada didesa ngarip para petani bebas menentukan harga jual (negosiasi) dengan pengepul dan KUB. Hal ini tergantung keadaan dari kualitas biji kopi itu sendiri. Petani pada saluran ke 1 menerima harga jual Rp. 21.500/kg dan pada saluran tataniaga yang ke 2 petani menerima harga jual Rp. 21.000-,. Pada tabel 9 menenjukan bahwa saluran tataniaga 1 memiliki nilai farmer's share yang lebih besar dibandingkan dengan saluran tataniaga ke 2 yaitu sebesar 98 persen.

\section{Rasio Keuntungan dan Biaya}

Rasio keuntungan adalah rasio yang digunakan untuk mengukur efektifitas perusahaan dalam mendapatkan keuntungan (Sangkala, 2009). Tabel 4 menunjukan bahwa rasio keuntungan dan biaya pada masing-masing lembaga menunjukan adanya persebaran keuntungan yang merata karena nilai yang dihasilkan lebih besar $0(>0)$.

Tabel 4. Rasio keuntungan dan biaya lembaga tataniaga kopi di Desa Ngarip

\begin{tabular}{lrcc}
\hline Saluran Tataniaga & Keuntungan $(\mathrm{Rp} / \mathrm{Kg})$ & $\begin{array}{c}\text { Biaya Tataniaga } \\
(\mathrm{Rp} / \mathrm{Kg})\end{array}$ & $\begin{array}{c}\text { Rasio Keuntungan \& } \\
\text { biaya }(п / \mathrm{C})\end{array}$ \\
\hline Saluran 1 & 17.229 & 727 & 23,7 \\
Petani & 361 & 140 & 2,6 \\
KUB & & & \\
Saluran 2 & 16.730 & 600 & 27,9 \\
Petani & 397 & 103 & 3,8 \\
Pengepul & 361 & 140 & 2,6 \\
KUB & & & \\
\hline
\end{tabular}

Tabel 4 terlihat semakin menyebarnya rasio keuntungan dan biaya pada masing - masing lembaga tataniaga kopi di Desa Ngarip maka dari segi oprasional sistem tataniaga bisa dikatakan efisien. Perhitungan di atas menunjukan saluran tataniaga 1 dan saluran tataniaga 2 adanya perseberan keuntungan yang merata karena nilai yang dihasilkan lebih besar $0(>0)$. Perhitungan rasio keuntungan dan biaya kedua saluran tataniaga di Desa Ngarip menunjukan adanya persebaran keuntungan yang merata dalam kisaran Rp 361,-Rp 397,-. Nilai rasio margin dan biaya tataniaga lebih tingi diterima pengepul daripada KUB.

Berdasarkan perhitungan margin tataniaga, farmer's share dan rasio keuntungan dan biaya dapat diketahui bahwa saluran tataniaga 1 memiliki margin tataniaga yang lebih rendah dibandingkan dengan saluran tataniaga 2. Hal ini disebabkan karena pada saluran ke 2 memiliki lembaga tataniaga yang lebih banyak dibandingakan dengan saluran tataniaga ke 1 . Saluran tataniaga ke 2 petani lebih memilih menjual hasil panen kopi mereka ke pengepul yang ada di Desa Ngarip dari pada menjual langsung ke KUB dengan selisih harga Rp500-. Hal ini dikarenakan selain adanya relasi sosial antar petani dan pengepul, juga karena 
lokasi KUB tersebut lebih jauh dan memerlukan biaya lebih untuk membawa hasil panen kopi sehingga petani harus mengeluarkan biaya lebih dalam penjualan hasil panen mereka.

Nilai farmer's Share saluran tataniaga 1 lebih besar dibandingkan saluran tataniaga 2 yang artinya perbandingan selisih harga diterima petani dengan yang diterima konsumen di tingkat desa Ngarip tidak begitu besar. Hal ini menunjukan saluran tataniaga 1 lebih efisien dari pada saluran tataniaga 2 walaupun nilai persebaran margin pada kedua saluran tersebut memiliki nilai marjin tataniaga yang tidak terpaut jauh. Penelitian ini sejalan dengan penelitian (Sujiwo, Wahyuningsih and Supardi, 2009) yang terdapat 2 saluran tataniaga, pada saluran pertama produsen langsung menjual kopi ke pedagang besar tidak melalui pedagang kecil sehingga harga yang diterima oleh produsen lebih besar dibandingkan produsen menjual kopi tersebut ke pedagang kecil. Saluran tataniaga yang melibatkan lebih banyak pelaku Lembaga tataniaga dapat menyebabkan terjadinya tataniaga yang tidak efisien. Tataniaga dapat dikatakan efisien apabila (1) mempunyai nilai total margin tataniaga yang lebih rendah karena berarti mampu menyampaikan hasil-hasil dari produsen kekonsumen akhir dengan biaya yang murah. (2) Mempunyai nilai Farmer's Share yang lebih dari saluran tataniaga satu dengan saluran tataniaga yang lain. (3) Mempunyai persebaran Rasio Keuntungan dan Biaya yang merata (Jumiati et al., 2013).

\section{KESIMPULAN DAN SARAN}

Kedua saluran tataniaga kopi di Desa Ngarip berdasarkan perhitungan rasio keuntungan dan biaya menunjukan adanya persebaran keuntungan yang relatif merata. Saluran tataniaga 1 lebih efisien dari pada saluran tataniaga 2 walaupun nilai persebaran margin pada kedua saluran tersebut memiliki nilai marjin tataniaga yang tidak terpaut jauh. Nilai farmer's share saluran tataniaga 1 lebih besar dibandingkan saluran tataniaga 2 namun perbandingan selisih harga diterima petani dengan yang diterima konsumen di tingkat Desa Ngarip tidak begitu besar.

Membangun kolektivitas penjualan petani kopi melalui KUB merupakan bagian integral dalam meningkatkan nilai ekonomi kopi. Keberlanjutan ekonomi kopi dalam membangun rantai nilai yang berkeadilan perlu terus dilakukan oleh berbagai pihak yang terlibat dalam aktivitas ekonomi kopi dari lini produksi di daerah sentra produksi hingga rantai perdagangan global.

\section{Ucapan Terima Kasih}

Ucapan terima kasih untuk Kepala Desa Ngarip, petani-petani kopi di Desa Ngarip dan Kelompok Usaha Bersama Sumberejo Tanggamus.

\section{DAFTAR PUSTAKA}

Arwati, S. (2016) 'Sistem Pemasaran Dan Nilai Tambah Produk Olahan Kabupaten Takalar Marketing Systems and Value-Added Products Sweet Potato in Sub District North Polongbangkeng Takalar Regency', 5(3), pp. 178-190.

Astuti, A. (2014) 'Analisis Margin Pemasaran Semangka di Daerah Istimewa Yogyakarta', AgroUPY, 6(1), pp. 27-37.

Badan Pusat Statistik. (2018) Lampung. Indonesia. Produk Domestik Regional Bruto (PDRB). Lampung.

Fitriani, Ismono, H. and Rosanti, N. (2012) 'Egg Production and Distribution', Jurnal ESAI, 6(2012), pp. 111.

Fuad, I. Z., Aenurofik, A. and Rosyid, A. (2015) 'Belenggu Tengkulak Atas Petani Pembudidayaan Lele: Relasi Patron-Klien Budidaya Lele di Wonotunggal Jawa Tengah', Jurnal Hukum Islam(JHI), 13(2), pp. 88-98. doi: 10.28918/jhi.v13i2.488. 
Mohammad Welly, dkk : Analisis Efesiensi Tataniaga Kopi di Desa Ngarip Kecamatan Ulubelu.....

Handayani, S. M. and Nurlaila, I. (2011) 'Analisis Pemasaran Susu Segar di Kabupaten Klaten', Sains Peternakan, 9(1), pp. 41-52. doi: 10.20961/sainspet.v9i1.4768.

Imelda, Dani Apriono, E. D. (2014) 'Analisis Efisiensi Saluran Pemasaran Ikan Lele di Desa Rasau Jaya 1 Kecamatan Rasau Jaya Kabupaten Kubu Raya’, Jurnal Sosial Ekonomi Pertanian, 1(3), pp. 29-36. doi: 10.26418/j.sea.v1i3.4363.

Jumiati, E. et al. (2013) 'Analisis Saluran Pemasaran dan Marjin Pemasaran Kelapa Dalam Di Daerah Perbatasan Kalimantan Timur', Jurnal Agrifor, 12(1), pp. 1-10. doi: 1412 - 6885.

Nainggolan, T. V., Suyatno, A. and Hutajulu, J. P. (2017) 'Analisis Pemasaran dan Transmisi Harga Cabai Rawit di Kabupaten Kubu Raya’, Sosial Ekonomi Pertanian, 1, pp. 1-11.

Noer, I., Fitriani, F. and Agus, A. (2012) 'The Coffee Market Integration in Lampung Province', Jurnal Ilmiah Esai, 6 No. 1(Januari 2012).

Prayitno, A.B, A. . H. S. S. (2013) 'Efisiensi Pemasaran Cabai Merah di Kecamatan Adiluwih Kabupaten Pringsewu Provinsi Lampung', J. Jiia, 1(1), pp. 53-59.

Rachmawati, R. (2011) 'Peranan Bauran Pemasaran (Marketing Mix) terhadap Peningkatan Penjualan (Sebuah Kajian terhadap Bisnis Restoran)', Jurnal Kompetensi Teknik, 2(2), pp. 143-150.

Sangkala, H. A. A. (2009) 'Analisis Kinerja Keuangan Berdasarkan Rasio Profitabilitas pada Perusahaan Pabrik Roti Tony Bakery Pare-Pare', Jurnal Ekonomi Balance Fekon Unismuh Makassar, pp. 1-19. doi: 10.1017/CBO9781107415324.004.

Sujiwo, J. T., Wahyuningsih, S. and Supardi, S. (2009) 'Efesiensi Pemasaran Kopi (Coffea sp) di Kecamatan Singorojo Kabupaten Kendal', Jurnal Ilmu- ilmu Pertanian, 5(2), pp. 72-85.

Utami, A. D. and Abidin, Z. (2019) 'Analisis Penentuan Biaya Pokok Produksi Olahan Kopi Robusta Di Koperasi Tirto Kencono Kabupaten Tanggamus The Basic Cost Production Of Robusta Coffee Processing At Tirto Kencono Cooperative Tanggamus Regency', Journal of Food System and Agribusiness Responden, 3(2), pp. 72-79. doi: http://dx.doi.org/10.25181/jofsa.I17i3.1550.

Yulida, R. (2012) 'Indonesian Journal of Agricultural Economics ( IJAE )', Indonesian Journal of Agricultural (IJAE), 3(2), pp. 135-154.

Arwati, S. (2016) 'SISTEM PEMASARAN DAN NILAI TAMBAH PRODUK OLAHAN KABUPATEN TAKALAR Marketing Systems and Value-Added Products Sweet Potato in Sub District North Polongbangkeng Takalar Regency', 5(3), pp. 178-190.

Astuti, A. (2014) 'Analisis Margin Pemasaran Semangka di Daerah Istimewa Yogyakarta', AgroUPY, 6(1), pp. 27-37.

Badan Pusat Statistik (2016) Statistik Lampung. Lampung. Indonesia. Produk Domestik Regional Bruto (PDRB). Lampung.

Fitriani, Ismono, H. and Rosanti, N. (2012) 'Egg Production and Distribution', Jurnal ESAI, 6(2012), pp. 111.

Fuad, I. Z., Aenurofik, A. and Rosyid, A. (2015) 'Belenggu Tengkulak Atas Petani Pembudidayaan Lele: Relasi Patron-Klien Budidaya Lele di Wonotunggal Jawa Tengah', Jurnal Hukum Islam(JHI), 13(2), pp. 88-98. doi: 10.28918/jhi.v13i2.488. 
Handayani, S. M. and Nurlaila, I. (2011) 'Analisis Pemasaran Susu Segar di Kabupaten Klaten', Sains Peternakan, 9(1), pp. 41-52. doi: 10.20961/sainspet.v9i1.4768.

Imelda, Dani Apriono, E. D. (2014) 'Analisis Efisiensi Saluran Pemasaran Ikan Lele di Desa Rasau Jaya 1 Kecamatan Rasau Jaya Kabupaten Kubu Raya', Jurnal Sosial Ekonomi Pertanian, 1(3), pp. 29-36. doi: 10.26418/j.sea.v1i3.4363.

Jumiati, E. et al. (2013) 'Analisis Saluran Pemasaran dan Marjin Pemasaran Kelapa Dalam Di Daerah Perbatasan Kalimantan Timur’, Jurnal Agrifor, 12(1), pp. 1-10. doi: 1412 - 6885.

Nainggolan, T. V., Suyatno, A. and Hutajulu, J. P. (2017) 'Analisis Pemasaran dan Transmisi Harga Cabai Rawit di Kabupaten Kubu Raya', Sosial Ekonomi Pertanian, 1, pp. 1-11.

Noer, I., Fitriani, F. and Agus, A. (2012) 'The Coffee Market Integration in Lampung Province', Jurnal Ilmiah Esai, 6 No. 1(Januari 2012).

Prayitno, A.B, A. . H. S. S. (2013) 'Efisiensi Pemasaran Cabai Merah di Kecamatan Adiluwih Kabupaten Pringsewu Provinsi Lampung', J. Jiia, 1(1), pp. 53-59.

Rachmawati, R. (2011) 'Peranan Bauran Pemasaran (Marketing Mix) terhadap Peningkatan Penjualan (Sebuah Kajian terhadap Bisnis Restoran)', Jurnal Kompetensi Teknik, 2(2), pp. 143-150.

Sangkala, H. A. A. (2009) 'Analisis Kinerja Keuangan Berdasarkan Rasio Profitabilitas pada Perusahaan Pabrik Roti Tony Bakery Pare-Pare’, Jurnal Ekonomi Balance Fekon Unismuh Makassar, pp. 1-19. doi: 10.1017/CBO9781107415324.004.

Sujiwo, J. T., Wahyuningsih, S. and Supardi, S. (2009) 'Efesiensi Pemasaran Kopi (Coffea sp) di Kecamatan Singorojo Kabupaten Kendal', Jurnal Ilmu- ilmu Pertanian, 5(2), pp. 72-85.

Utami, A. D. and Abidin, Z. (2019) 'Analisis Penentuan Biaya Pokok Produksi Olahan Kopi Robusta Di Koperasi Tirto Kencono Kabupaten Tanggamus The Basic Cost Production Of Robusta Coffee Processing At Tirto Kencono Cooperative Tanggamus Regency', Journal of Food System and Agribusiness Responden, 3(2), pp. 72-79. doi: http://dx.doi.org/10.25181/jofsa.I17i3.1550.

Yulida, R. (2012) 'Indonesian Journal of Agricultural Economics ( IJAE )', Indonesian Journal of Agricultural (IJAE), 3(2), pp. 135-154. 